\title{
Physiological and Mechanical Role of 14-3-3 Lambda in Arabidopsis thaliana during Drought Stress
}

\author{
Bela Peethambaran ${ }^{1}$, Tsai Chi Li ${ }^{1}$, Phil Dzugan ${ }^{1}$, Wenxi Xiang ${ }^{2}, \&$ Ronald Balsamo ${ }^{2}$ \\ ${ }^{1}$ Department of Biological Sciences, University of Sciences in Philadelphia, Philadelphia, USA \\ ${ }^{2}$ Department of Biology, Villanova University, Villanova, USA \\ Correspondence: Bela Peethambaran, Department of Biology, 600S 43rd street, University of Sciences in \\ Philadelphia, Philadelphia, PA 19085, USA. E-mail: b.peethambaran@usp.edu
}

$\begin{array}{lr}\text { Received: April 28,2012 } & \text { Accepted: May 22, } 2012 \quad \text { Online Published: July 11, } 2012 \\ \text { doi:10.5539/jas.v4n8p149 } & \text { URL: http://dx.doi.org/10.5539/jas.v4n8p149 }\end{array}$

\begin{abstract}
Climate changes this century due to global warming compel a greater understanding of molecular mechanisms for plant resistance to drought conditions. Plants undergo changes in their anatomy, morphology, mechanical properties and also in their gene expression in response to environmental stress. Using reverse genetics, anatomy and molecular biology approaches, the role of a 14-3-3 protein isoform in the presence of simulated drought conditions in the model organism Arabidopsis thaliana was investigated. The14-3-3 proteins serve the function of signal transduction in eukaryotes and their role in several abiotic and biotic stress conditions have been previously reported. In this study we used 12 isoforms of 14-3-3 that are expressed and well characterized in A. thaliana to determine which isoform of 14-3-3 contributed to drought stress resistance. A phenotypic assay for drought was conducted by growing all the mutants of the isoforms in media with Abscisic acid (ABA). The 14-3-3 lambda ( $\lambda$ ) mutants showed deficiency in lateral root growth. Further investigations revealed significant differences in ion leakage, absolute water content, water potential and tensile strength in mutants deficient in $14-3-3 \lambda$ versus

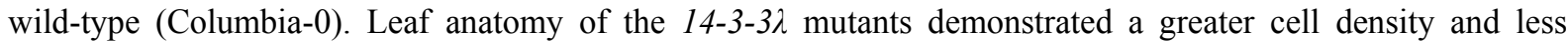
intracellular airspace compared to Col- 0 in well-hydrated and drought conditions. Roots of the 14-3-3 $\lambda$ mutants exhibited collapsed epidermal, endodermal and cortical cells in both wet and dry conditions. We thus conclude that 14-3-3 $\lambda$ is involved in drought tolerance and contributes in the development of roots and leaves crucial for drought resistance.
\end{abstract}

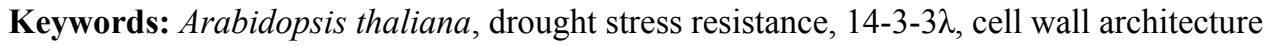

\section{Introduction}

Drought stress is one of the most common environmental stresses that reduce agricultural productivity (Beck et al. 2007). To alleviate this problem, considerable efforts have been directed towards understanding the various physiological and biochemical pathways plants employ during drought stress. These responses include the production of reactive oxygen species, stomatal closure, repression of cell growth, altered photosynthesis and activation of respiration (Beck et al., 2007). Signal transducers such as 14-3-3 proteins are involved in alerting downstream cellular components, triggering a stress resistant response and thereby enabling greater tolerance of biotic and abiotic stress (Roberts et al., 2002).

The 14-3-3 proteins are a group of conserved regulatory proteins found in all eukaryotic organisms. These proteins can form homo or hetero dimers and each of the monomers can interact with other client proteins. Binding of the 14-3-3 proteins to the client proteins leads to changes in its activity, localization, or aid in its interaction with other proteins to perform a physiological function. For example, 14-3-3 binds to nitrate reductase (Huber et al., 1996), starch synthase (Sehnke et al., 2001), sucrose phosphate synthase (Moorhead et al., 2002) and induce conformational changes that can make the client protein more active or inactive (Chung et al., 1999). In plants, studies have shown that 14-3-3 can also regulate primary metabolism, ion transport, cellular trafficking, enzyme activities and gene expression (Ferl, 1996; Sehnke et al., 2002). Due to its innumerable clients and its ability to affect several physiological functions, 14-3-3 has been demonstrated to have important roles in alleviating biotic and abiotic stress. The roles of 14-3-3 proteins have been established in abiotic stresses such as high salt concentration, cold and osmotic stress where the gene expression of the 14-3-3 was altered in response to stress. Up regulation of a 14-3-3 gene occurred in rice callus and seedlings in the presence of either high salt concentrations or low temperatures (Kidou et al., 1993). Studies in sugar beet cells have shown a re-distribution of 
14-3-3 proteins during cold and osmotic stresses (Babakov et al., 2000; Chelysheva et al., 1999). These proteins have also been shown to help in maintaining ion homeostasis in plant cells. Potassium channel and H+ATPase transport proteins in the guard cells of $A$. thaliana are under the regulation of a 14-3-3 lending further evidence that they may serve a role in drought tolerance through regulation of these membrane proteins (Fuglsang et al., 2007; Schoonheim et al., 2007; van den Wijngaard et al., 2005). Specifically, association of 14-3-3 with H+ATPase occurs at the C-terminus in a phosphorylation-dependent manner (Bunney et al., 2001). This activation results in membrane hyper-polarizations that lead to influx of $\mathrm{K}+$, water uptake, and stomatal opening. Furthermore, it was demonstrated that 14-3-3 binds to outward rectifying $\mathrm{K}+$ channels (Booij et al., 1999). This study also revealed that an increase in the cellular 14-3-3 concentrations in response to abiotic stress altered the $\mathrm{K}+$ transport and may have contributed in the restoration of membrane potential.

Several studies have indicated indirect evidence of a role of 14-3-3 in the action of ABA. For example, in embryonic roots ABA inactivates a 14-3-3 activated inward K+ channel (Van den Wijingaard et al., 2005). ABA signaling effector viviparous 1 (VP1), which triggers signaling through the hormone ABA to control the closure of guard cells under drought conditions also interacts with a 14-3-3 as revealed using a yeast two hybrid assay (Schultz et al., 1998). Additionally, 14-3-3 works as an adaptor in the interaction of VP1 acting as a transcriptional activator with the trans-acting factors of the ABF/AREB/ABI5 family that bind to ABRE (Abscisic acid response elements) (Himmelbach et al., 2003). In barley, 14-3-3 proteins were shown to interact with the transcription factors HvABF1, HvABF2, HvABF3, and HvABF15. This study demonstrated its role in ABA-dependent signal transduction during seed dormancy and germination (Schoonheim et al., 2007). In the same study, ABA and 14-3-3 have also been demonstrated to interact in a tightly coupled manner with each affecting the expression of the other. In Vicia faba, ABA induces binding of a 14-3-3 to a $61 \mathrm{kDa}$ protein present in the guard cells which was speculated to act as a substrate for ABA-activated protein kinase (AAPK), which in turn was activated by ABA in guard cells during drought stress (Yohei Takahashi. et al., 2007).

Numerous studies have suggested possible roles of 14-3-3 proteins in drought signaling networks. For example, over-expression of $A$. thaliana 14-3-3 $\lambda$ in cotton has produced transgenic plants with a greener phenotype during

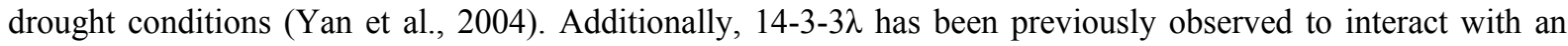
oxidative-stress protective protein such as ascorbate peroxidase 3(APX3) and with a disease-resistance associated protein ankyrin repeat containing protein 2 (AKR2) (Yan et al., 2002; Zhang et al., 1997). However, the

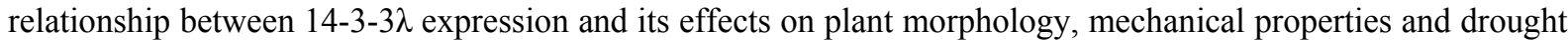
resistance has yet to be fully explored. We investigated the response of twelve 14-3-3 isoforms T-DNA homozygous mutants (epsilon, iota, omicron, psi, pi, omega, mu, nu, chi, lambda, upsilon and kappa) to treatment with $\mathrm{ABA}$ and compared the phenotype to wild-type plants (Col-0). Many drought responses are regulated by ABA, and in previous studies (De Smet et al., 2003; Deak et al., 2005; Xiong et al., 2006) it was demonstrated that $\mathrm{ABA}$ and osmotic stress regulates lateral root development. In the study conducted by Xiong et al. 2006, ABA deficient mutants such as $a b a 1, a b a 2, a b a 3$ and ABA response mutant's abi2, abi3, abi5 showed some defects in root development under the control conditions and also showed variations in the lateral root growth in response to treatment with $\mathrm{ABA}$. These mutants were also tested for their drought response and all the above $a b a$ mutants exhibited an enhanced response to ABA by reducing lateral root elongation. From the above study, it was seen that mutants hypersensitive to $\mathrm{ABA}$ were more drought tolerant and those which were insensitive to $\mathrm{ABA}$ were drought sensitive (Xiong et al., 2006). Hence, we performed a similar phenotypic assay to test which of the 14-3-3

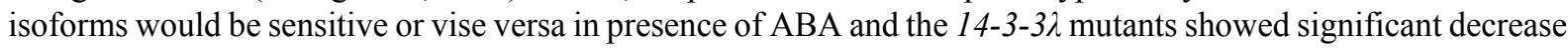
in lateral root growth which is a similar response to the previously examined ABA deficient mutants (Xiong et al., 2006). We selected this 14-3-3 isoform to further understand its contribution to plant resistance to drought stress. In this study we utilized reverse genetics, biomechanics, comparative anatomy and molecular tools to further

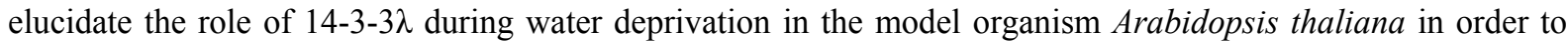
clarify potential roles of this protein in a variety of stress-related cellular functions.

\section{Materials and Methods}

\subsection{Plant Genotypes and Growth Conditions}

Wild type Columbia (Col-0), T-DNA knockouts of 14-3-3 isoforms nu (SALK_114711, SALK_084141), kappa (SALK_148929, SALK_000496), mu (SALK_083139, SALK_004455) lambda (14-3-3 $\lambda 1$ SALK_129554, 14-3-3 $\bar{\lambda} 2$ SALK_075219), upsilon (SALK_014690, SALK_152018), epsilon (SALK_129798, SALK_082560), chi (SALK_142285, SALK_018664), iota (SALK_110798, SALK_099442), pi (SALK_0419458, SALK_053026), psi (SALK_001646, SALK_001716), omicron (SALK_123168, SALK_064569), omega (SAIL_904_D03, GABI_116F06) Arabidopsis plants were grown on autoclaved BM2 Germinating Mix (Berger Inc., Quebec Canada) in a growth chamber at $24^{\circ} \mathrm{C}$ with $75 \%$ relative humidity and a $12 \mathrm{~h}$ photoperiod. 


\subsection{Phenotype Assay}

To evaluate if any of the twelve 14-3-3 isoforms had a role in drought tolerance we used a reverse genetic approach. Two T-DNA mutants from the 14-3-3 isoforms lambda, epsilon, iota, omicron, psi, omega, mu, nu, chi, upsilon, kappa and pi were ordered from The Arabidopsis Biological Resource Center (http://abrc.osu.edu/). These mutants were genotyped to ensure they were homozygous to the T-DNA insertions and only the confirmed lines were subjected to drought conditions using a method modified from (Xiong et al., 2006). Briefly, seeds of Arabidopsis thaliana wild-type (Col-0) and 14-3-3 isoform mutants were surface sterilized and planted on MS medium (1.2\% agar, $3 \%$ sucrose). Five-day old seedlings were then transferred individually into petri-plates containing Murashige and Skoog (Fisher Scientific, PA) basal medium and micronutrients $(1.0 \mathrm{mM} \mathrm{CaCl} 2,0.5$ $\mathrm{mM} \mathrm{MgSO}$, $0.4 \mathrm{mM} \mathrm{KH}_{2} \mathrm{PO}_{4}, 6.0 \mathrm{mM} \mathrm{KNO}_{3}$, and $7.0 \mathrm{mM} \mathrm{NH}_{4} \mathrm{NO}_{3}$ ) were added at full strength and $\mathrm{pH} 5.7$. $\operatorname{ABA}(0.1 \mu \mathrm{M})$ was added after autoclaving the medium. Five to six seedlings each of the 14-3-3 T-DNA knockout mutant and wild-type (Col-0) were grown on one half of the plate. The petri-plates were incubated in the growth chambers $\left(24^{\circ} \mathrm{C}, 75 \%\right.$ humidity) allowing the plants to grow vertically. Growth was monitored for $12-15$ days and the lateral roots were measured on the fifth day after transfer to the ABA treatment plates. Lateral root length was measured from the primary root growth attachment to its end from images using ImageJ software from National Institutes of Health (NIH) (http://rsb.info.nih.gov/hin-image). The total number and length of lateral roots of each individual plant was calculated and the average was used as an index of lateral root growth.

\subsection{Simple RT-PCR to Confirm Homozygous to T-DNA Insertions}

For simple RT-PCR, the RNA was isolated using Trizol methods described as follows. One gm of tissue was flash frozen in liquid nitrogen and grounded into fine powder. One microliter of Trizol was added on the ground tissue. Once thawed, the material was collected in an eppendorf tube and centrifuged at $10 \mathrm{rcf}$ for 5 minutes. About $0.2 \mathrm{ml}$ of chloroform was added to the supernatant in a separate tube. After vortexing briefly the samples were incubated at room temperature for 10 minutes before centrifuging for $10 \mathrm{rcf}$. The top layer was moved into a new tube and $0.25 \mathrm{ml}$ of RNA precipitation solution $(0.8 \mathrm{M}$ Sodium citrate $/ 1.2 \mathrm{M} \mathrm{NaCl})$ as well as $0.25 \mathrm{ml}$ of isopropanol was added. The resulting RNA pellet was washed twice with $75 \%$ ethanol before air drying. RNA pellets were dissolved in RNAse free water. The RNA was converted to cDNA using a RETRO Script kit (Ambion, Foster city, CA). The primers were designed specific to Arabidopsis lambda cDNA (AT5G10450) and a PCR was conducted for 28 cycles. Primers targeting a specific region of 14-3-3 $\lambda$ were amplified using the forward primer 'TGCTGGAGCGAGTGAGTCTA' and reverse primer 'AGCCTGTTTGGCCATGTTAC'. An actin primer for gene ACT2 (AT3G18780) 'TCCAGTGTTGTTGGTAGGCCA' and 'TCTCAGCACCAATCGTGATGAC' was run at the same time to control for loading differences.

\subsection{Drought Tolerance Test}

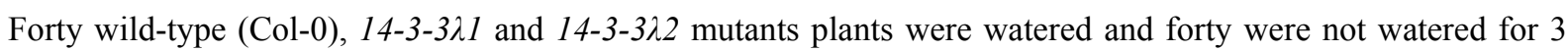
weeks. The occurrence of wilting leaves for both the wild-type and the mutants were noted and photographed from the beginning of drought treatment until the moisture levels in the pots were less than $40 \%$ of field capacity for the soil mix. The moisture levels were determined using a Wescor psycrometer/hygrometer (Wescor Biomedical systems, Logan, Utah). These plants were also used after 7 days of drought treatment to test for their cell ion leakage, relative water content, water potential, and tensile strength.

\subsection{Electrolyte Leakage}

Electrical conductivity measurements were performed using an EP11/pH pDS meter (Myron L. Carlsbad, CA) on

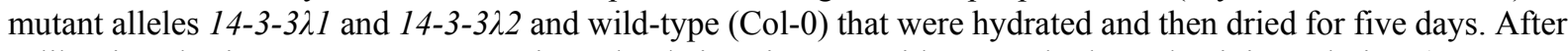
calibrating the instrument to 6888 micromhos/microsiemens with a standard conductivity solution (Myron L. Carlsbad, CA), the sensor and sensor well were rinsed three times with DI water. Leaf samples were excised from

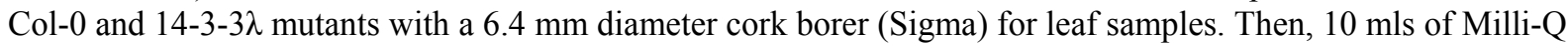
water $(\sim 1 \mu \mathrm{S} / \mathrm{cm})$ were added to a $25 \mathrm{ml}$ glass sample bottle with two leaf discs, and the bottle was gently agitated for $10 \mathrm{~min}$. The water and leaf sample were transferred to the meter's sensor well, with care given to ensure that the liquid covered the sensor. The sensor well was rinsed and dried twice between each reading.

\subsection{Relative Water Content}

Relative water content (RWC) was determined as a percentage compared to fully hydrated tissue. Briefly, whole lamina was excised from plants and immediately weighed (experimental weight) and measured (length, width, thickness). They were then pulled to catastrophic failure in the tensometer. The two pieces were then placed in deionized water in sealed containers for $24 \mathrm{~h}$ and then were-weighed (fully hydrated weight). The experimental weights were then divided by the fully hydrated weights and multiplied by 100 to determine the percent RWC of the samples at the time of the tensile strength tests. 


\subsection{Water Potential}

Water potential was determined for fully hydrated, partially hydrated and fully dehydrated samples of wild type and mutant strains using a PMS model 1003 plant pressure chamber (PMS Instrument, Corvallis, Oregon, USA).

\subsection{Tensile Strength}

Leaf tensile strength was determined for wild type and both lambda mutant strains using a custom-built tensometer (Balsamo et al. 2005; 2006). Briefly, whole laminas were secured in custom made clamps and attached to a scale. Force was applied at the rate of $0.1 \mathrm{~N} / \mathrm{s}$ until catastrophic failure. Leaf thickness and width was measured at the fracture face using digital calipers and the tensile strength calculated in megapascals $\left(\mathrm{N} / \mathrm{mm}^{2}\right)$.

\subsection{Light Microscopy}

Leaf sections of mature $A$. thaliana leaves were cut into $1-2 \mathrm{~mm}^{2}$ sections, and placed immediately into sealed 25 $\mathrm{ml}$ jars with $2 \mathrm{ml}$ of a $2 \%$ gluteraldahyde solution in $100 \mathrm{mM}$ phosphate buffer (pH 6.8). The vial was gently agitated for 2.5 hours, after which the fixative solution was removed and washed $3 \mathrm{X}$ with $100 \mathrm{mM}$ phosphate buffer $(\mathrm{pH}$ 6.8). A rapid (1 hr) serial dehydration in increasing concentrations of ethanol was followed by incubation in $2 \mathrm{ml}$ of $100 \%$ ethanol and the vial was agitated for 20 minutes. This was repeated three times. Resin embedding was initiated with five rounds of $800 \mu$ additions of Spurrs epoxy resin (Ted Pella, Redding, CA) with 20 minutes of agitation, after which, $50 \%$ of the total volume of the vial was resin. The solution in the vial was reduced to $1 \mathrm{ml}$, and $1 \mathrm{ml}$ of pure resin was added, followed by 4 hours of agitation. This process was repeated a total of four times. After a final replacement of the solution in the vial with $100 \%$ Spurrs, individual plant sections were removed from the resin and transferred to gelatin capsules and filled and sealed with resin. After baking in a $60^{\circ} \mathrm{C}$ oven for 48 hours, sections were cut from the pills, adhered to wooden dowels, and allowed to set for 24 hours. These were then manually trimmed and the shaped resin blocks were sectioned on a MT 6000 Sorvall microtome with a glass blade into $500 \mathrm{~nm}$ thick sections. Sections were removed with a metal loop from the water bath and transferred to glass slides. The sections were then stained with toluidine blue $\mathrm{O}$ to distinguish lignified from the non-lignified tissues, and allowed to dry on a hot plate for 2 minutes before being rinsed. These sections were then immersed in emmersion oil, a glass coverslip was placed on top of the slides, and tissue samples were imaged using an Olympus BH-2 brightfield microscope and SPOT INSIGHT QE camera. Using ImageJ, the percentage of intercellular spaces in the leaf lamina of wild-type and $14-3-3 \lambda$ were counted using a grid of $1 \mathrm{~mm}^{2}$ and corrected for magnification.

\subsection{Transmission Electron Microscopy}

Samples for transmission electron microscopy were fixed and washed as above. The samples were incubated in 1\% OsO4 in mM cacodylate buffer for $2 \mathrm{~h}$, dehydrated in an EtOH series, and embedded in Spurr's resin. Sections of 50-75 nM thickness were cut on a Sorvall 6000 ultramicrotome and transferred to copper grids. Grids were then stained using standard protocols ( $1 \%$ aqueous uranyl acetate followed by $2 \%$ aqueous lead citrate). Grids were evaluated and digitally imaged on a Hitachi 7600 STEM microscope.

\subsection{Statistics}

Unpaired t-tests were performed using Mann-Whitney test (http://elegans.swmed.edu/ leon/stats/utest). The unpaired t-tests were used to measure differences between Col-0 and all of the 14-3-3 mutants on the basis of lateral root growth, tensile strength, ion leakage, and intercellular air space.

\section{Results}

\subsection{Drought Phenotypic Assays}

To screen for distinguishing phenotypes among the 14-3-3 isoform mutants, T-DNA knockouts homozygous to insertion from twelve 14-3-3 isoforms were grown on MS medium and agar containing $0.1 \mu \mathrm{M}$ ABA. Out of all the

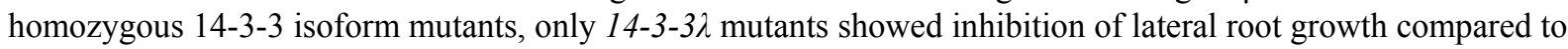

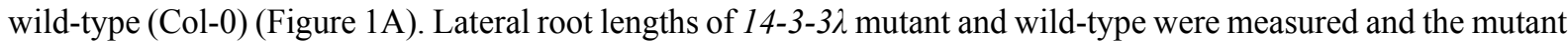

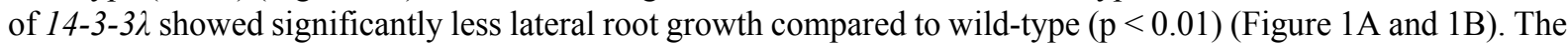
deficient lateral growth phenotype was similar in anatomical appearance to ABA-biosynthetic deficient and ABA response mutants as previously described by Xiong et al., (2006).

\subsection{Simple RT PCR to Confirm T-DNA Homozygous Insertion Mutants}

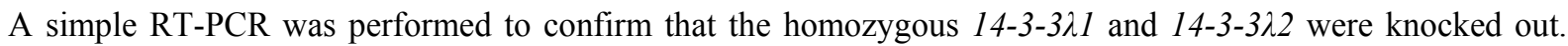
There was negligible expression in the mutants when amplified using primers that were specific for the Arabidopsis 14-3-3 lambda cDNA (Figure 2). 


\subsection{Drought Phenotype test}

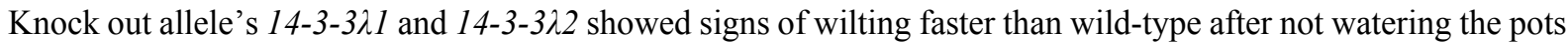
for 7 days (Figure 3). To further investigate the drought response of the mutant versus the wild-type we performed RWC, water potential, tensile strength, leaf and root architecture, and lignin content studies.

\subsection{Relative Water Content (RWC) of the 14-3-3 Mutant Alleles Compared to Wild-type (Col-0)}

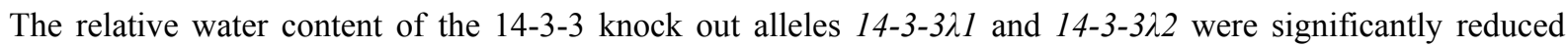
$(\mathrm{p}<0.05)$ compared to the wild-type $(\mathrm{Col}-0)$ under drought conditions (Figure 4$)$.

\subsection{Water Potential of 14-3-3ג Mutants Compared to Wild-type (Col-0)}

In the hydrated conditions, the water potential of both the mutant alleles did not differ significantly from wild-type.

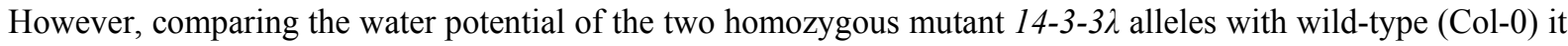
was observed that there is significant increase in water potential (i.e. more negative values) during dehydration which indicates the 14-3-3 knockout alleles are under increased drought stress compared to wild-type $(\mathrm{p}<0.001)$ (Figure 5).

\subsection{Ion Leakage in 14-3-3ג Mutants Compared to Wild-type (Col-0)}

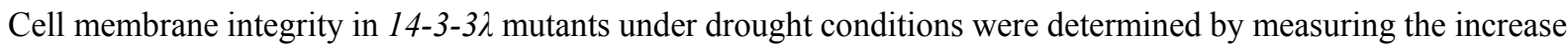

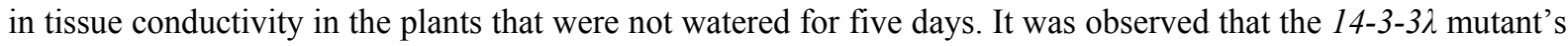

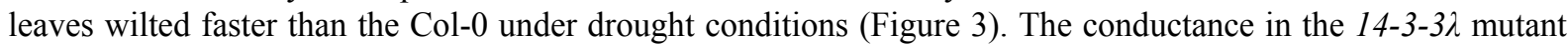
leaves in hydrated conditions compared to Col-0 did not show any significant difference (Figure 6). But in the drought conditions, conductivity in $14-3-3 \lambda$ mutants was significantly higher than Col-0 $(\mathrm{p}<0.01)$ (Figure 6). Comparison of the ion conductance within each genotype, there was a significant increase in all the genotypes (Figure 6)

\subsection{Tensile Strength of 14-3-3ג Mutants Compared to Wild-type (Col-0)}

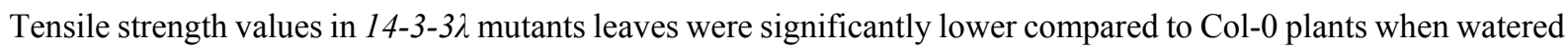
regularly $(\mathrm{p}<0.001)$ (Figure 7$)$. However, during drought conditions there was a significant increase in the tensile

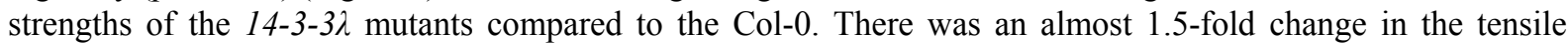

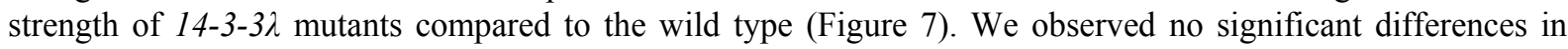

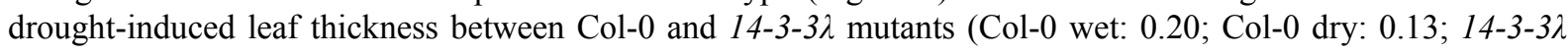

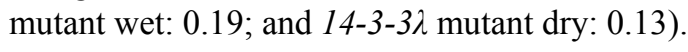

\subsection{Leaf Architecture of 14-3-3ג Mutants}

Three different leaves of the same age and three different sections of the same leaf were examined for both mutants and wild-type. The sections were from the middle of the lamina from relatively the same position. No significant

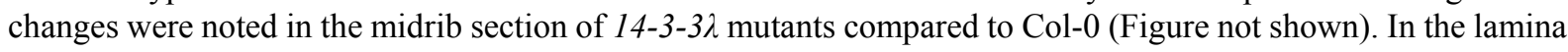
leaf sections of the Col-0, the cells were spatially more dispersed compared to $14-3-3 \lambda$ (Figure 8A). The average intercellular spaces in wild-type were approximately $12.8 \%$ while in $14-3-3 \lambda$ mutant it was $5.5 \%$. Cell density in

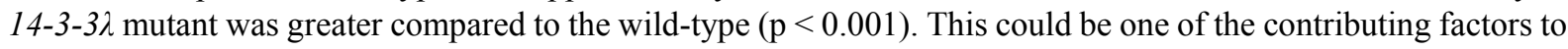

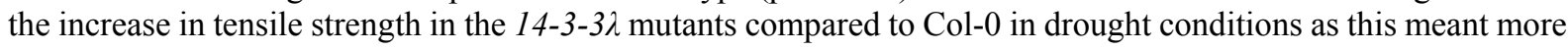
cellulose per area which would have contributed in making the leaves more difficult to tear. The amounts of lignin

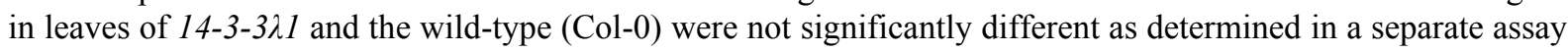
(not shown). Transmission electron microscope images showed a typical cell wall architecture of leaf mesophyll cells for control (col) plants and 14-3-3 $\lambda$ lambda mutants with an altered microfibril spacing and no clear middle lamella (Figure 8B). The cell wall architecture of the mutants treated with drought was also investigated using

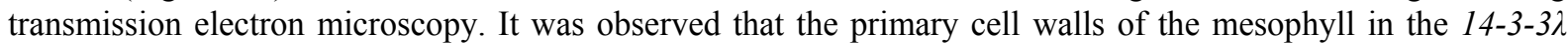
mutant was thinner than in controls and resulted in a higher degree of cell wall deformations compared to Col-0 (Figure 8C).

\subsection{Root Architecture of 14-3-3 $\lambda$ Mutant}

Three different roots of the mutants and wild-type were examined in different parts of the roots. These sections were observed all the way from the apex to the tip of the root. The images in figure 9 are from the sections taken from the middle of the roots. Col-0 control samples showed a radial arrangement of epidermal, cortex, endodermis, pericycle, protoxylem, protophloem, procambium, and central cells (Figure 9A) (please see this reference for cells arrangement Dolan et al., 1993, Figure 1). In drought conditions, Col-0 root sections exhibited a collapse of the

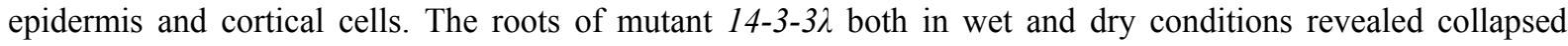
epidermal, cortical and endodermal cells (Figure 9A on the right). The architecture of the vascular bundles also appeared distorted in the mutants compared to the controls. Lignin depositions were observed (blue color) on the 


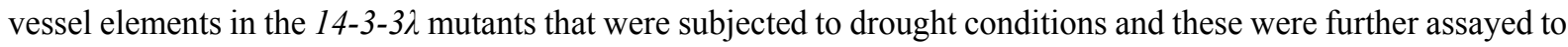
measure the percent lignin content. However, the lignin assay performed on the root tissues did not reveal any

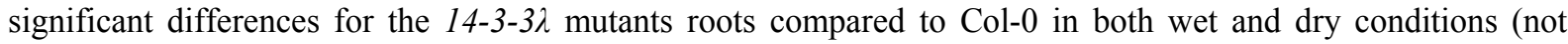

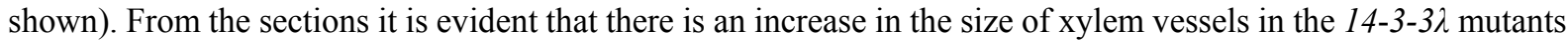
compared to Col-0 in both wet and drought treated roots (Figure 9B). Vascular bundles of the wild-type and

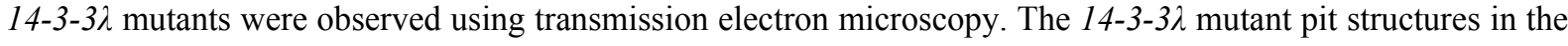
vessel elements were collapsed compared to those in wild-type in both wet and dry conditions (Figure 9C).

\subsection{Lignin Content in Stems of 14-3-3ג Mutants}

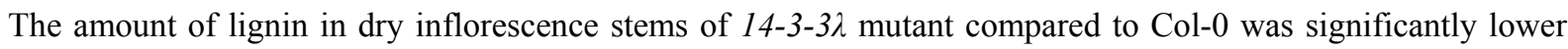
$(\mathrm{p}<0.001)$ (Figure 10)

\section{Discussion}

Mechanical properties of leaves such as tensile strength and physiological assessments such as relative water content, ion leakage and membrane stability are important indicators of tolerance to drought stress e in plants (Balsamo et al., 2006; Tas, S., \& Tas, B., 2007). The volume of water that a leaf loses in relation to the corresponding reduction of leaf water potential is a reliable indicator of drought resistance (Maxwell \& Redmann 1978; Davis \& Mooney 1986; Balsamo et al., 2006). Leaves which show smaller changes in water content for a given reduction in cellular water potential are generally regarded as more drought-resistant (Jarvis \& Jarvis 1963;

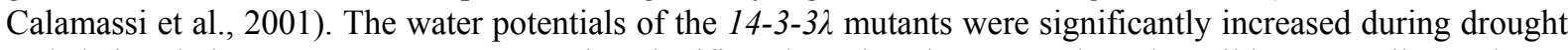
and their relative water contents were also significantly reduced compared to the wild-type. Cell membrane disruption caused by drought is typically assessed by measuring ion leakage (Caruso et al., 1999). The conductance of ions was increased significantly in 14-3-3 mutants compared to wild-type in drought conditions. This indicates a possible role of 14-3-3 $\lambda$ in maintaining cell membrane integrity.

The tensile strength of 14-3-3 $\lambda$ mutants under drought conditions also showed a significant increase compared to the wild-type. Tensile strength is generally attributed to the amount of lignin and cellulose in the cell wall and tissue architecture (Balsamo et al., 2003; Balsamo et al., 2006). But there was no significant differences observed

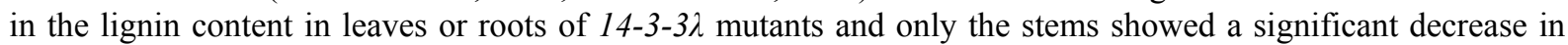
lignin concentrations. Quantification of lignin from leaf, root, and stem tissues suggests that the differences in lignin depositions in the vascular tissues in the mutants that were not noticeable by toluidine staining at the light microscope level in leaves or roots was different in the major stem axis between the controls and the mutant

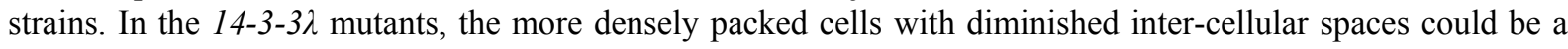
contributing factor to the increased tensile strength under dry conditions. The increase in cell density relates to a proportional increase in cellulose content which under dry conditions become more tough and harder to tear.

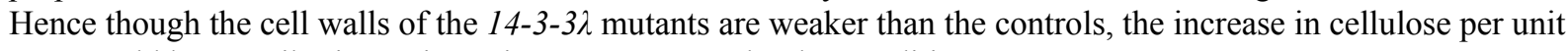
area would be contributing to its resistance to tear under dry conditions.

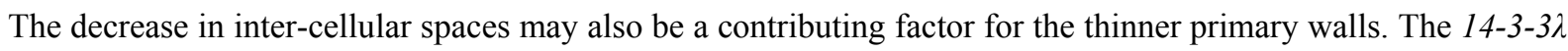
mutants may have insufficient intercellular space to bend or stretch during stress, which may also explain the relative increase in tensile strength during drought. Maintenance of membrane integrity has been used as a measure

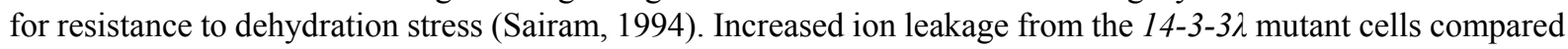

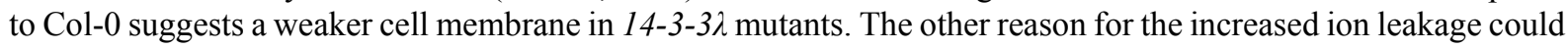
be the $\mathrm{H}+\mathrm{ATPase}$ and $\mathrm{K}+$ pumps on the plasma membrane and tonoplast which has been shown to interact with 14-3-3 in several plant species (Fuglsang et al., 2007; Gobert et al., 2007; van den Wijngaard et al., 2005). For

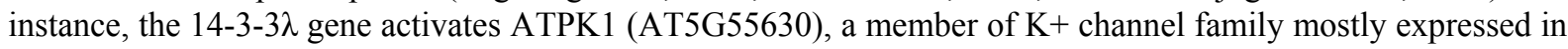
the tonoplast where it mediates the $\mathrm{K}+$ selective currents between cytoplasmic and vacuolar components (Rapp \& Hedrich, 2007). It was also reported in tobacco that over-expression of two 14-3-3 proteins isolated from Vicia $f a b a$ transformed into tobacco protoplasts showed enhanced $\mathrm{K}+$ conductance compared to wild-type protoplast (Saalbach et al., 1997). Tomato 14-3-3 isoforms TFT4 and TFT7 have been shown to modulate outward rectifying $\mathrm{K}+$ channels in cell suspensions (Booij et al., 1999). These outward rectifying $\mathrm{K}+$ channels are important to reset the membrane potential upon depolarization of the membrane potential caused by environmental changes.

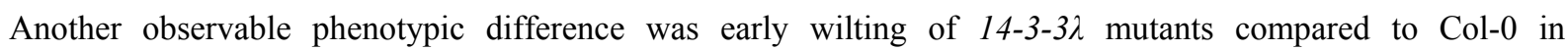
water-deprived conditions. This is likely due to a weaker plasma membrane as reflected by the increased ion

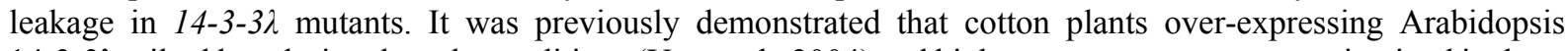
14-3-3 $\lambda$ wilted less during drought conditions (Yan et al., 2004) and higher turgor pressure was maintained in these cotton transgenics. Therefore, the transgenic cottons had less leaf damage after drought and recovery cycles. Studies conducted by de-Araujo et al., (1996) and Moorhead et al., (2002) suggested that 14-3-3 proteins regulate trehalose-6-phosphate synthase, which is necessary for conversion of glucose-6-phosphate to trehalose which 
itself was demonstrated to play a protective role in desiccation tolerance (de-Araujo 1996; Moorhead et al., 2002).

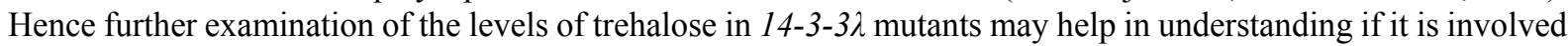
in regulation of trehalose-6-phosphate synthase.

The alteration of root architecture and the leaf cell density indicates a possible interaction or regulation of developmental genes by 14-3-3 $\lambda$. In a previous study it was demonstrated using a yeast-two hybrid assay that a leucine rich receptor (LRR) somatic embryogeneis receptor (SERK1) interacts with cell division cycle 48

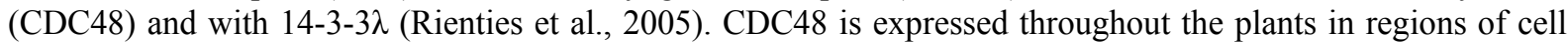
division such as the vegetative shoot, root, floral inflorescence and flowers, and in rapidly growing cells (Rienties et al., 2005). 14-3-3 has also been shown to regulate activity of mitochondrial and chloroplast $F_{0} F_{1}$ ATP synthase via a phosphorylation-dependent binding. It was suggested that 14-3-3s provided a mechanism for regulation of ATP synthase activity in response to anoxia in roots and changes in nutrient supply (Bunney et al., 2001).

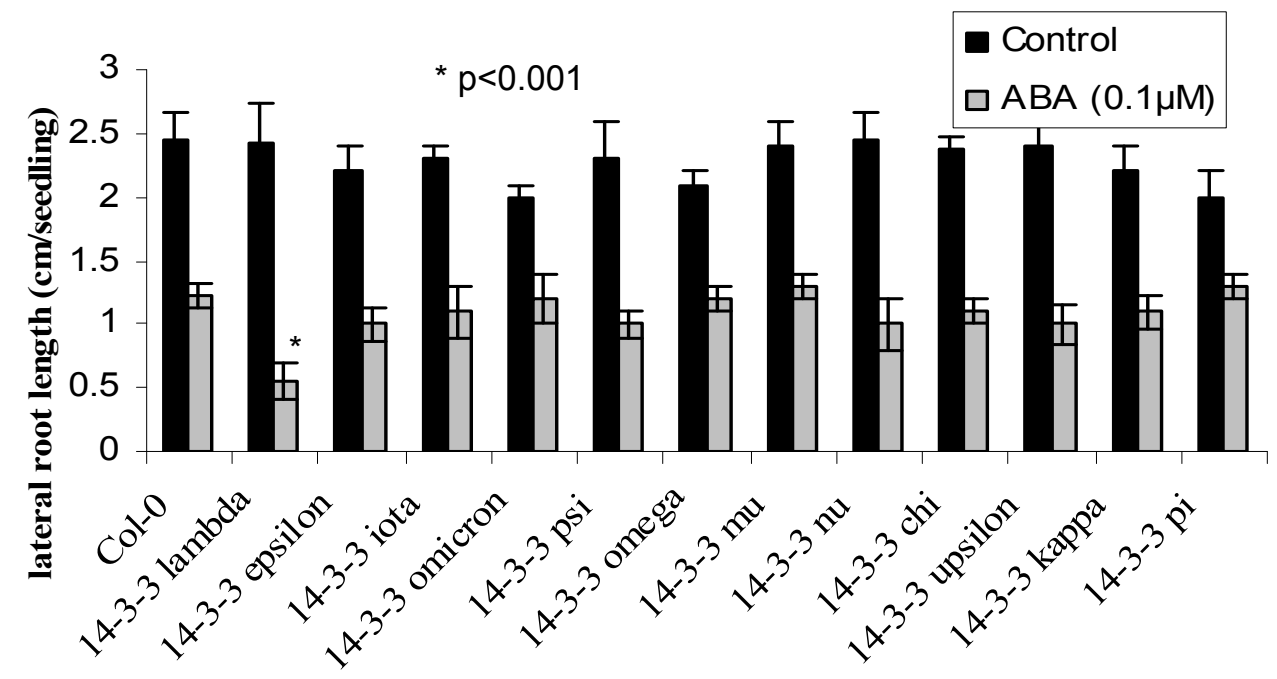

Figure 1A. Average lateral root growth in 14-3-3 isoform mutants of forty plants compared to A. thaliana wild-type $(\mathrm{Col}-0)$ after growing them on media with and without ABA $(0.1 \mu \mathrm{M})$. Five day old seedlings germinated in MS medium were transferred to $\mathrm{ABA}$ treatment plates and the lateral root lengths were measured after 5 days of transfer. A paired $t$ test was used to calculate the significant difference in growth between wild-type and 14-3-3 mutants. The

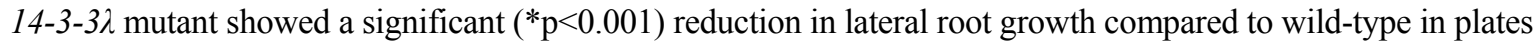
having ABA. The error bars represent standard deviation $(n=40)$ for all the mutants and wild-type

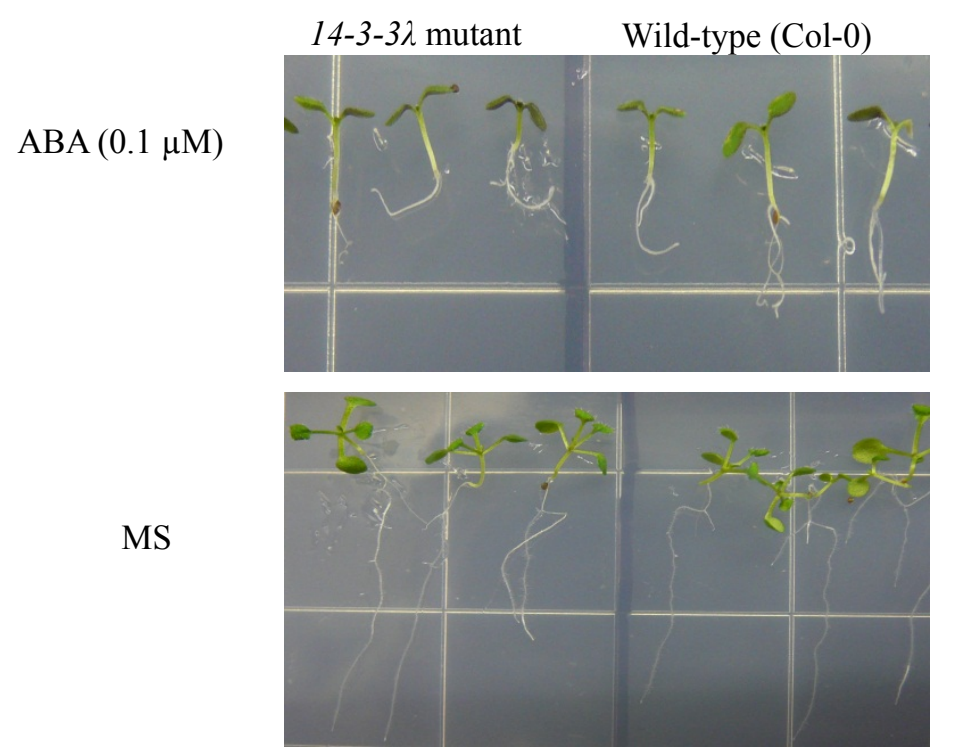

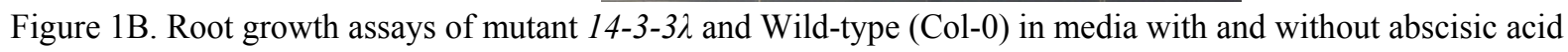
(ABA) 


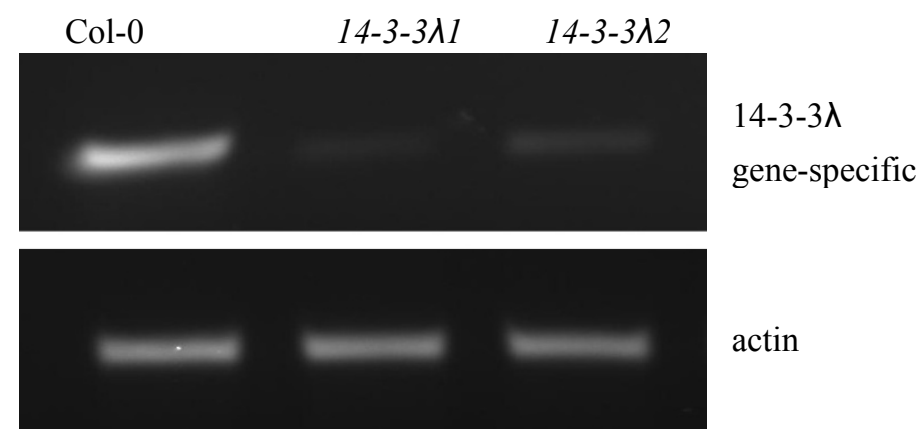

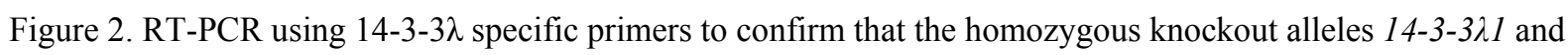
14-3-3 22 (SALK_129554 and SALK_075219) have negligible mRNA expression
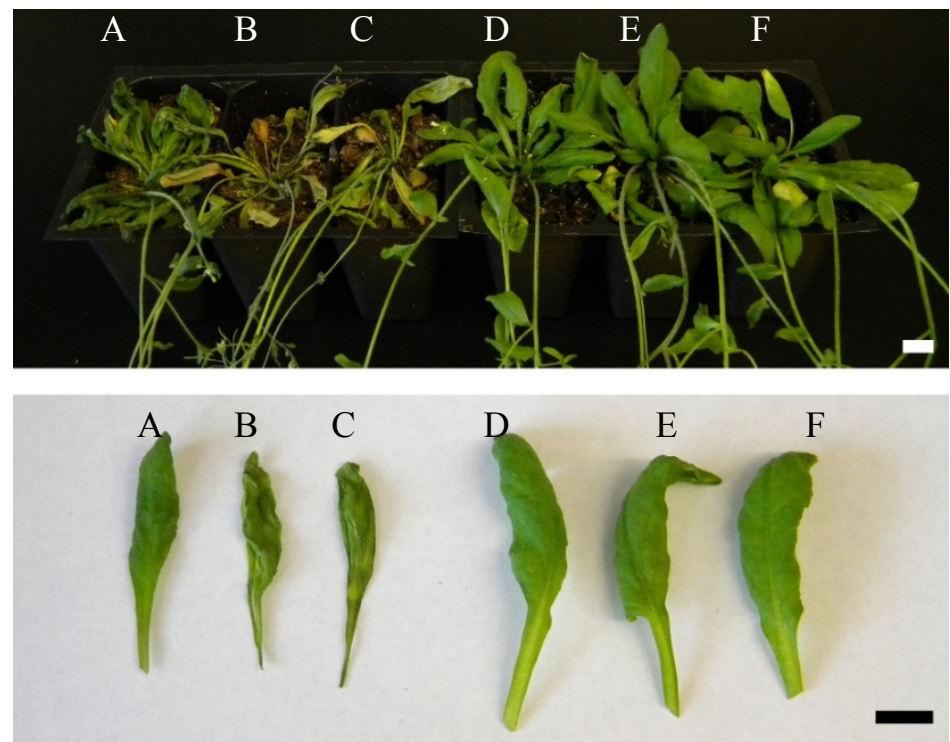

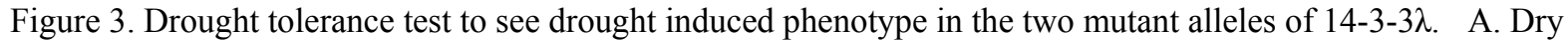

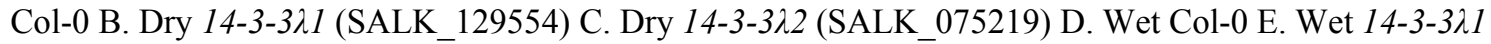

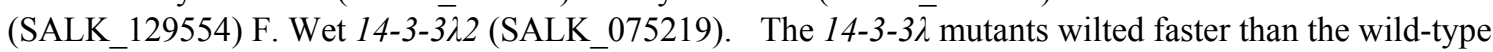
$(\overline{\mathrm{C}}$ ol- -0$)$. Scale bars $=1 \mathrm{~cm}$

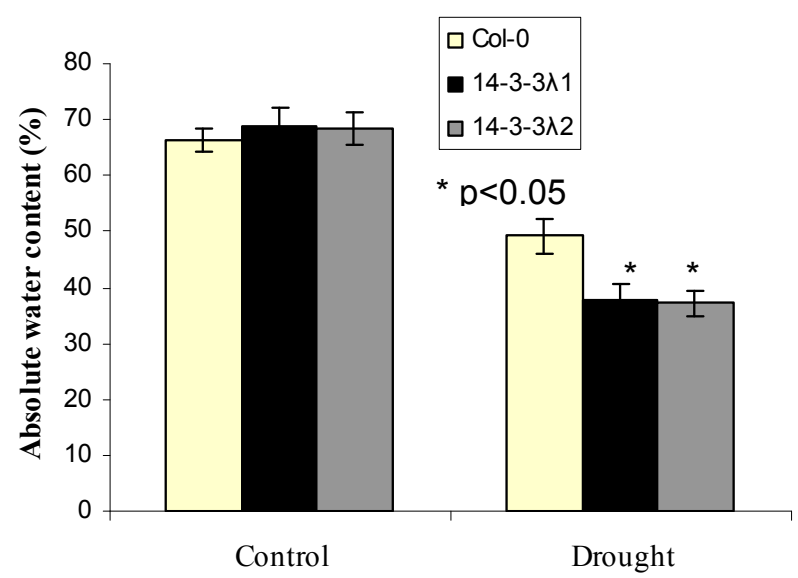

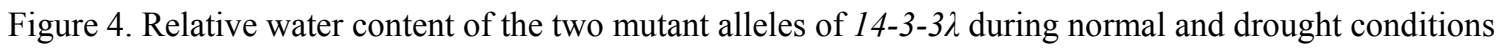
compared to wild-type $A$. thaliana (Col-0). The error bars represent standard deviation ( $\mathrm{n}=30$ for both the mutant alleles and wild-type). The difference in the absolute water content of Col- 0 and the knockouts which were drought treated were significantly different $(\mathrm{p}<0.05)$ 


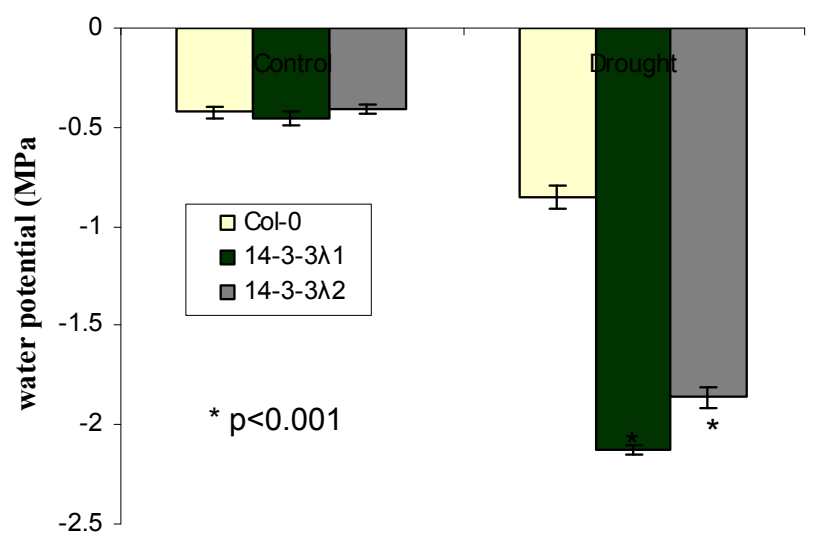

Figure 5. Water potential of the two mutant alleles of $14-3-3 \lambda$ during normal and drought conditions compared to wild-type $A$. thaliana $(\mathrm{Col}-0)$. The error bars represent standard deviation $(\mathrm{n}=30$ for both the mutant alleles and wild-type). The $14-3-3 \lambda$ mutants had a significantly high water potential $(\mathrm{p}<0.001)$ compared to wild-type (Col-0)

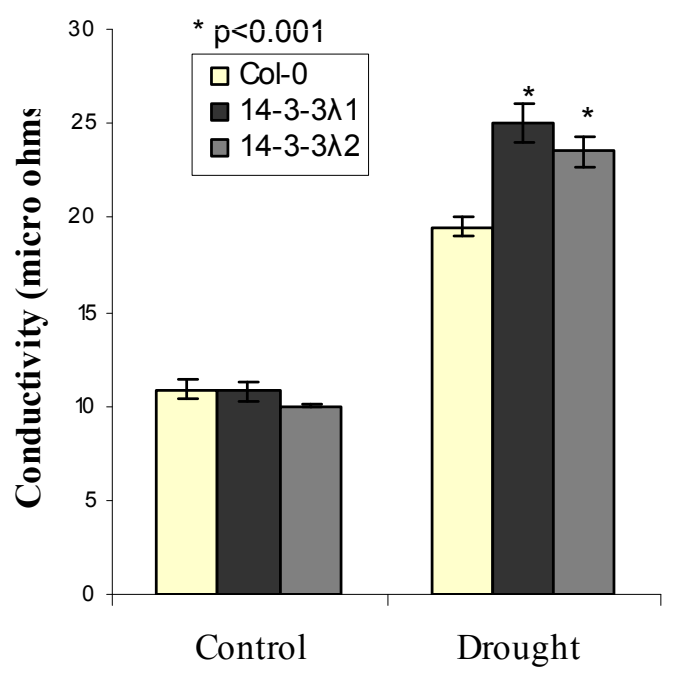

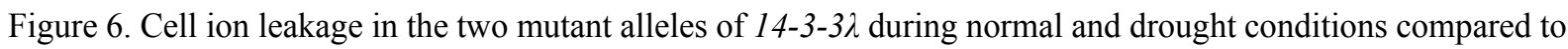
wild-type $A$. thaliana (Col-0). The error bars represent standard deviation ( $\mathrm{n}=30$ for both the mutant alleles and wild-type). The cell ion leakage that represents one of the measures of stress tolerance to drought was significantly higher in the 14-3-3 $\lambda$ mutants compared to wild-type after drought treatment 


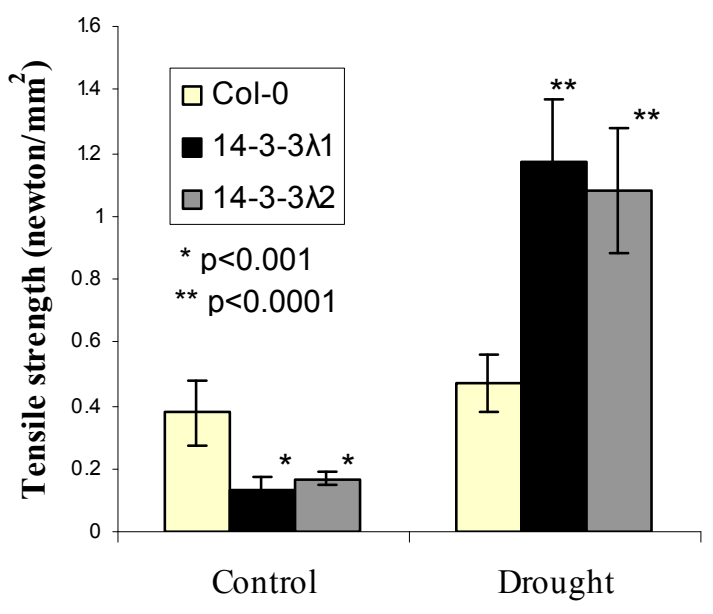

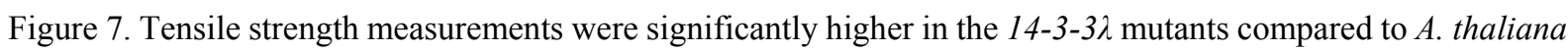
wild-type (Col-0) in drought conditions. In well hydrated conditions, the tensile strength of the mutants were significantly less than Col- $0(\mathrm{p}<0.001)$. In drought, the tensile strength in Col-0 did not increase but increased almost 1.5 times in $14-3-3 \lambda$ mutants $(\mathrm{p}<0.0001)$. The error bars represent standard deviation ( $\mathrm{n}=30$ for both the mutant alleles and wild-type)
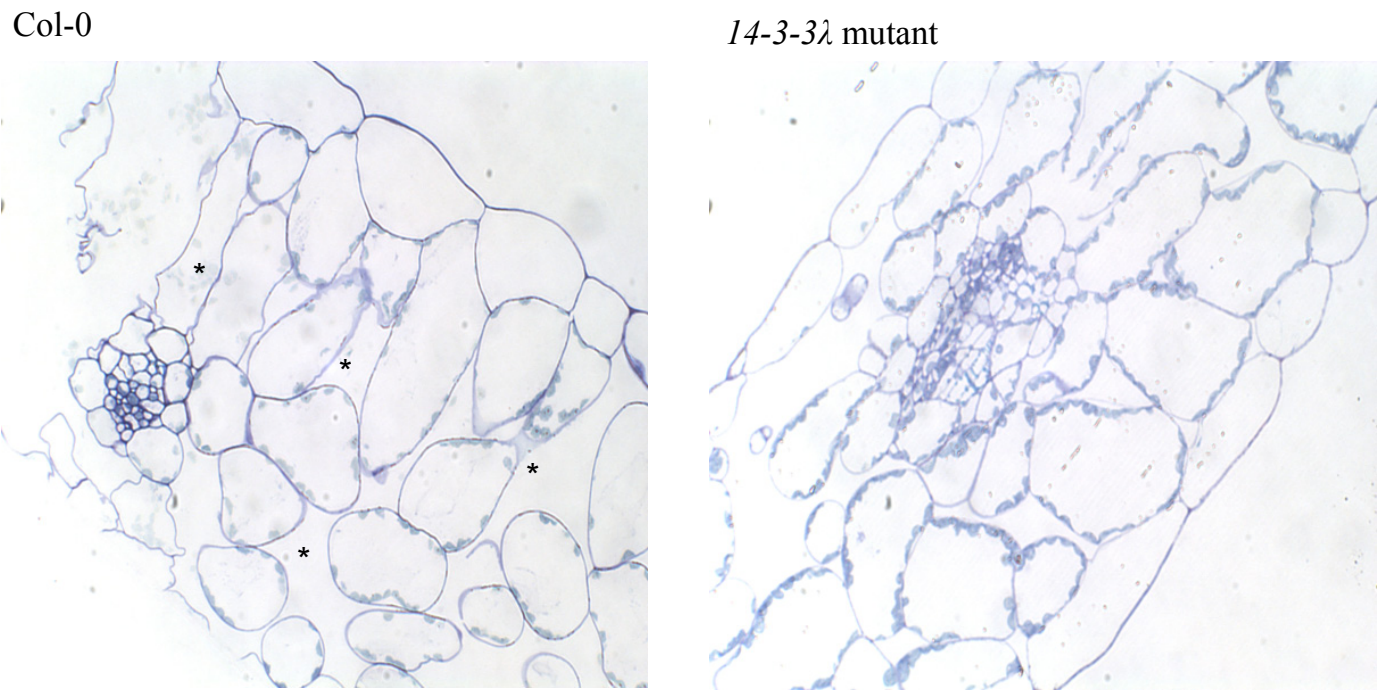

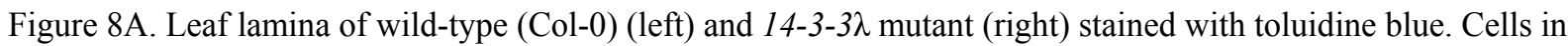
the wild-type show more intracellular spaces, while the cells in the mutant are densely packed. Both images photographed at $40 \mathrm{X}$. The asterix indicate intracellular spaces 

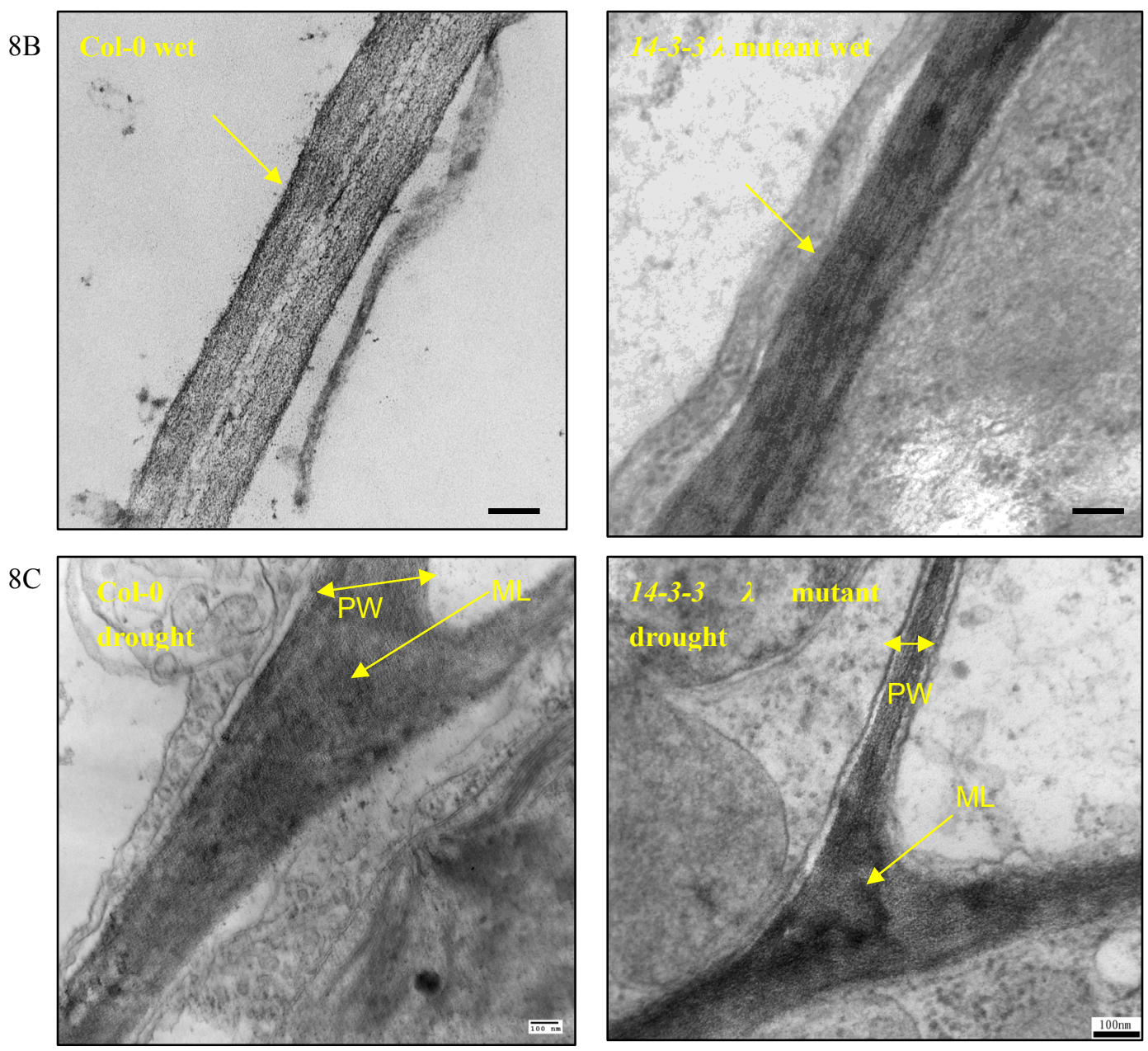

Figure 8B. Transmission electron microscope images showing typical cell wall architecture of leaf mesophyll cells for control (col) plants (left) and 14-3-3 $\lambda$ lambda mutants (right) which show altered microfibril spacing and no clear middle lamella. Arrows indicate cell walls; bars indicate scale $(100 \mathrm{~nm})$

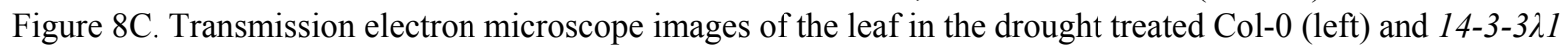

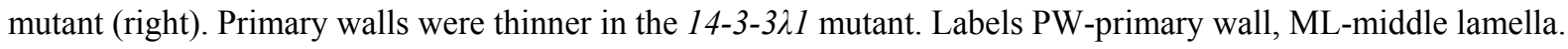
Bars indicate scale $(100 \mathrm{~nm})$ 
$9 \mathrm{~A}$
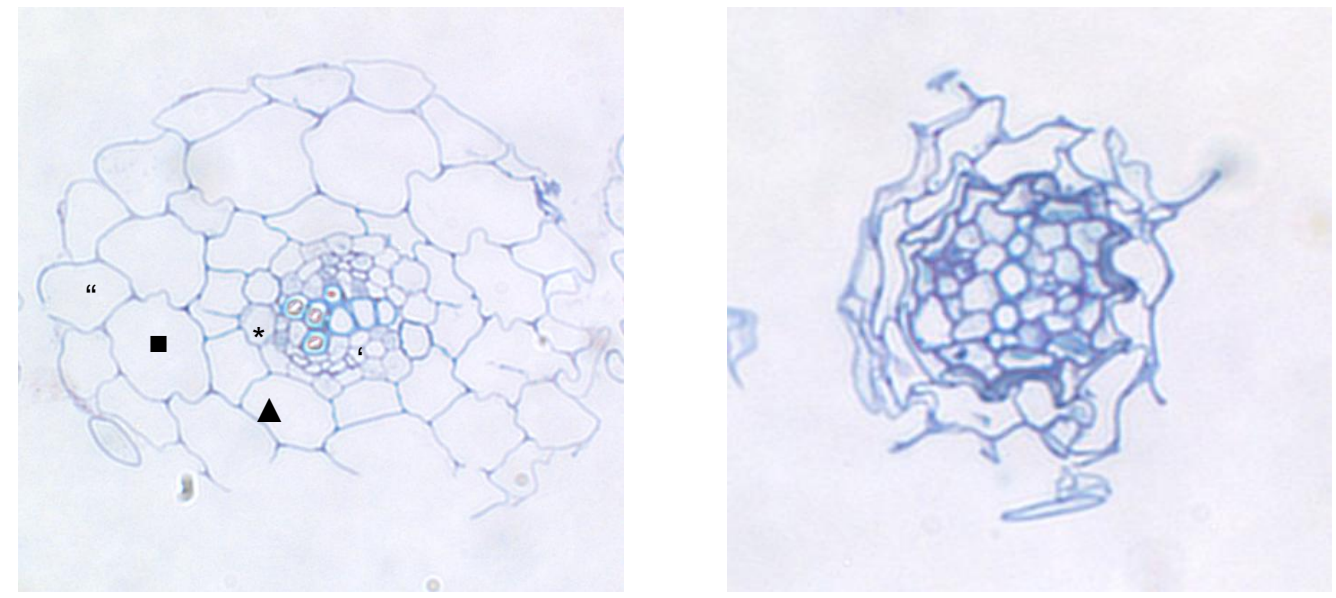

Wild-type (Col-0)-wet

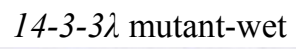

9B

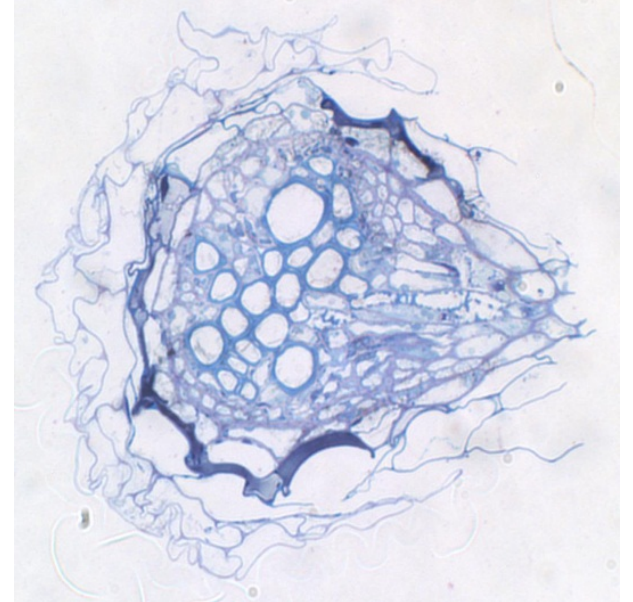

Wild-type (Col-0)-Drought

9C

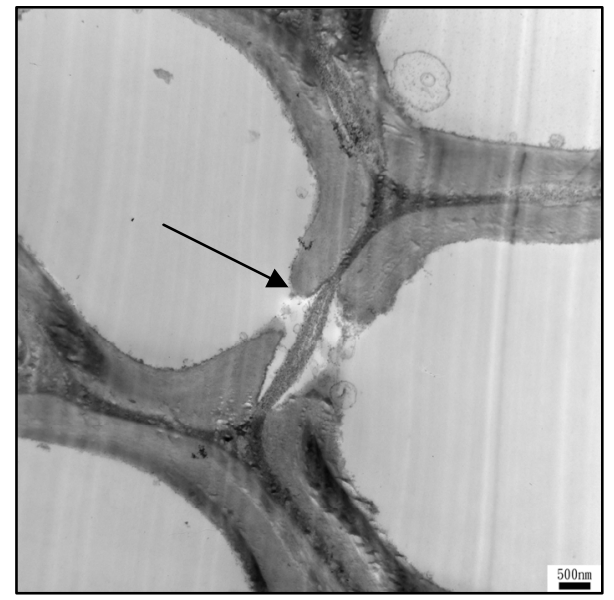

ESM- Wild-type (Col-0)-Drought

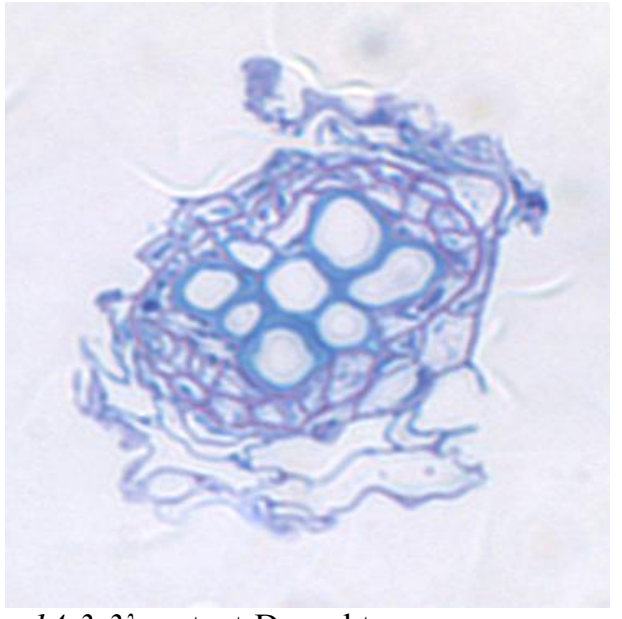

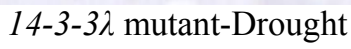

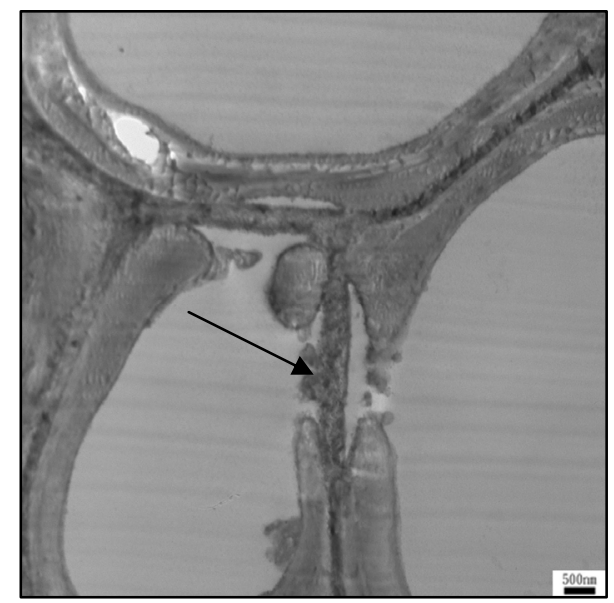

ESM- 14-3-3 $\lambda$ mutant Drought

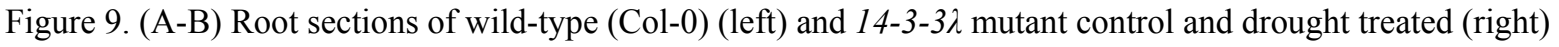
stained with toluidine blue. A radial arrangement of epidermal (“), cortex ( $\mathbf{a})$, endodermis $(\mathbf{\Delta})$, pericycle $(*)$, protoxylem $(\uparrow)$, protophloem $(\downarrow)$, procambium('), and central cells observed in Col-0 wet root sections. All photographs were taken at $100 \mathrm{X}$

Figure 9C. Transmission electron microscope images of the vascular bundles of the wild-type (left) and the

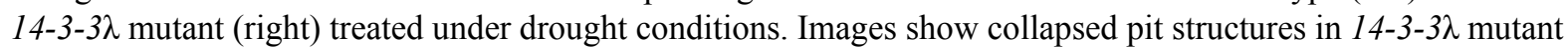




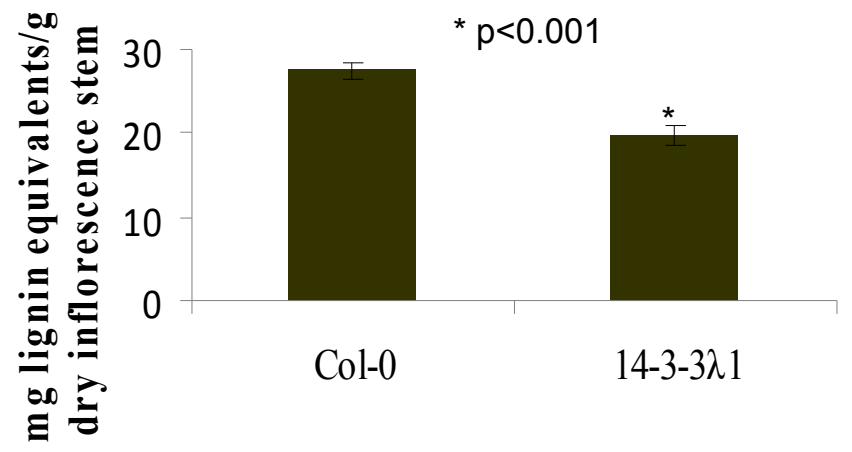

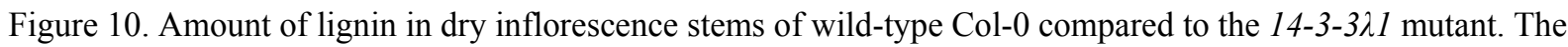
error bars represent standard deviation ( $\mathrm{n}=5$ for the mutant and wild-type). The lignin content in the stems of 14-3-3 mutants was significantly reduced compared to wild-type (Col-0)

\section{Conclusions}

Our study demonstrates a potential functional role of $14-3-3 \lambda$ in the development of root and leaf architecture.

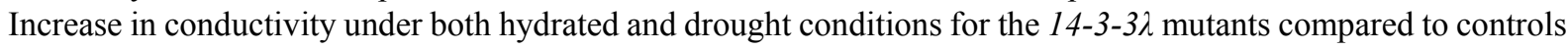
assert a role of 14-3-3 $\lambda$ in the maintenance of cell membrane homeostasis during drought. Tensile strength tests suggest its high cell density results in increased cellulose content but the cell wall architecture in 14-3-3 $\lambda$ mutants is altered and, hence emphasizes its role in cell wall development. This gene has a pivotal role in maintaining integrity of plant cells during drought stress particularly since it has been shown to interact with cell division genes such as CDC 48 and SERK1 (Rienties et al., 2005). The collapse of the epidermal, endodermal and cortex cells in the roots of the 14-3-3 mutants also provide evidence of its role in root development.

From our studies it is evident that 14-3-3 $\lambda$ has an effect on either ABA response or synthesis which was observed by the decrease in the lateral growth of roots after treatment with ABA. Several studies have indicated that 14-3-3 binds to transcription factors that regulate ABA synthesis. ABA has been known to be a key hormone regulating several drought responses. Hence it would be interesting to further characterize the role of 14-3-3 in ABA dependent responses during drought stress. Further studies are needed to help define its role in development and its effects on drought stress resistance.

\section{Acknowledgements}

We thank Dr. Robert Ferl (University of Florida) and Dr. Hong Zhang (Texas Tech University) for providing us with 14-3-3 antibodies. Our appreciation for all the help extended by Dr. Norm Dollahon and Ms Sally Shrom (Villanova University) with the microscopy procedures. We would like to thank Alex Mercedo and Vaishali Desai, undergraduates in Peethambaran lab for their contributions in the study of some of the parameters. Our thanks to Dr. Jane Glazebrook (University of Minnesota) for sharing some of the 14-3-3 T-DNA knockout seeds. This research was supported by funds from University of Sciences in Philadelphia and from Villanova University and in part by the USDA/CREES NRI grant 2008-35100-04413 and by the National Science Foundation under grant IOS 0950374 to Ronald Balsamo.

\section{References}

Babakov, A. V., Chelysheva, V. V., Klychnikov, O. I., Zorinyanz, S. E., Trofimova, M. S., \& De Boer, A. H. (2000). Involvement of 14-3-3 proteins in the osmotic regulation of H-ATPase in plant plasma membranes. Plant, 211, 446-448. http://dx.doi.org/10.1104/pp.105.061275

Balsamo, R. A., Bauer, A. M., Davis, S. D., \& Rice, B. M. (2003). Leaf biomechanics, morphology, and anatomy of the deciduous mesophyte Prunus serrulata (Rosaceae) and the evergreen sclerophyllous shrub Heteromeles arbutifolia (Rosaceae). Am J Bot, 90, 72-77. http://dx.doi.org/10.3732/ajb.90.1.72

Balsamo, R., Vander Willigen, C., Boyko, W., \& Farrant, J. (2005). Anomalous leaf tensile properties during dehydration may help elucidate mechanisms of desiccation tolerance in Eragrostis nindensis. Physiol Plantarum, 124, 336-342. http://dx.doi.org/10.1093/aob/mc1068 
Balsamo, R. A., Willigen, C. V., Bauer, A. M., \& Farrant, J. (2006). Drought tolerance of selected Eragrostis species correlates with leaf tensile properties. Annals of Botany, 97, 985-991. http://dx.crossref.org/10.1093\%2Faob\%2Fmc1068

Beck, E. H., Fettig, S., Knake, C., Hartig, K., \& Bhattarai, T. (2007). Specific and unspecific responses of plants to cold and drought stress. J Biosci, 32, 501-510. http://dx.doi.org/10.1007/s12038-007-0049-5

Booij, P. P., Roberts, M. R., Vogelzang, S. A., Kraayenhof, R., \& de Boer, A. H. (1999). 14-3-3 proteins double the number of outward-rectifying K channels available for activation in tomato cells. The Plant Journal, 20, 673. http://dx.doi.org/10.1046/j.1365-313X.1999.00643.x

Bunney, T. D., Van Walraven, H. S., \& De Boer, A. H. (2001). 14-3-3 protein is a regulator of the mitochondrial and chloroplast ATP synthase. Proc Natl Acad Sci $U$ S A, 98, 4249. http://dx.doi:org/10.1073/pnas.061437498

Calamassi, R., Rocca, G. D., Falusi, M., Paoletti, E., \& Strati, S. (2001). Resistance to water stress in seedlings of eight European provenances of Pinus halepensis Mill. Ann For Sci, 58, 663-672. http://dx.doi.org/10.1051/forest:2001153

Caruso, C., Chilosi, G., Caporale, C., Leonardi, L., Bertini, L., Magro, P., \& Buonocore, V. (1999). Induction of pathogenesis-related proteins in germinating wheat seeds infected with Fusarium culmorum. Plant Science, 140, 87-97. http://dx.doi.org/10.1016/S0168-9452(98)00199-X

Chelysheva, V. V., Smolenskaya, I. N., Trofimova, M. C., Babakov, A. V., \& Muromtsev, G. S. (1999). Role of the 14-3-3 proteins in the regulation of $\mathrm{H}$-ATPase activity in the plasma membrane of suspension-cultured sugar beet cells under cold stress. FEBS Lett., 456, 22-26.

Chung, H. J., Sehnke, P. C., Ferl, R. J., \& Anderson, H. W. (1999). The 14-3-3 proteins: cellular regulators of plant metabolism. Trends Plant Sci, 4, 367-371. http://dx.doi.org/10.1016/S1360-1385(99)01462-4

Davis, S. D., \& Mooney, H. A. (1986). Tissue water relations of four co-occurring chaparral shrubs. Oecologia (Berlin), 70, 527-535. http://dx.doi.org/10.1007/BF00379899

de-Araujo, P. S. (1996). The role of trehalose in cell stress. Braz J Med Biol Res, 29, 873-875.

De Smet, I., Signora, L., Beeckman, T., Inze, D., Foyer, C. H., \& Zhang, H. (2003). An abscisic acid-sensitive checkpoint in lateral root development of Arabidopsis. Plant $J$, 33, 543-555. http://dx.doi.org.10.1046/j.1365-313X.2003.01652.x

Deak, K. I., \& Malamy, J. (2005). Osmotic regulation of root system architecture. Plant J., 43, 17-28. http://dx.doiorg.10.1111/j.1365-313X.2005.02425.x

Dolan, L., Janmaat, K., Willemsen, V., Linstead, P., Poethig, S., Roberts, K., \& Scheres, B. (1993). Cellular organization of Arabidopsis root. Development, 119, 71-84.

Ferl, R. J. (1996). 14-3-3 proteins and signal transduction. Annual Review of Plant Biology, 47, 49-73. http://dx.doi.org.10.1146/annurev.arplant.47.1.49

Fuglsang, A. T., Guo, Y., Cuin, T. A., Qiu, Q., Song, C., Kristiansen, K. A., ... Anderson, H. W. (2007). Arabidopsis protein kinase PKS5 inhibits the plasma membrane $\mathrm{H}+$-ATPase by preventing interaction with 14-3-3 protein. Plant Cell, 19,1617-1634.

Gobert, A., Isayenkov, S., Voelker, C., Czempinski, K., \& Maathuis, F. J. M. (2007). The two-pore channel TPK1 gene encodes the vacuolar K conductance and plays a role in K homeostasis. Proc Natl Acad Sci U S A, 104, 10726-10731. http://dx.doi.org.10.1073/pnas.0702595104

Himmelbach, A., Yang, Y., \& Grill, E. (2003). Relay and control of abscisic acid signaling. Curr. Opin. Plant Biol., 6, 70-479. http://dx.doi.org/10.1016/S1369-5266(03)00090-6

Huber, S. C., Bachmann, M., \& Huber, J. L. (1996). Post-translational regulation of nitrate reductase activity: a role for $\mathrm{Ca} 2$ and 14-3-3 proteins. Trends Plant Sci., 1, 432-438. http://dx.doi.org/10.1016/S1360-1385(96)10046-7

Jarvis, P. G., \& Jarvis, M. S. (1963). The water relations of tree seedlings. IV. Some aspects of the tissue water relations and drought resistance. Physiol Plant, 16, 501-517. http://dx.doi.10.1111/j.1399-3054.1963.tb08327.x

Kidou, S., Umeda, M., Kato, A., \& Uchimiya, H. (1993). Isolation and characterization of a rice cDNA similar to the bovine brain-specific 14-3-3 protein gene. Plant Mol Biol, 21, 191-194. http://dx.doi.org/10.1007/BF00039631 
Maxwell, J. O., \& Redmann, R. E. (1978). Leaf Water Potential, Component Potentials and Relative Water Content in a Xeric Grass. Agropyron dasystachyum (Hook.) Scribn, 35, 277-284.

Moorhead, G., Douglas, P., Cotelle, V., Harthill, J., Morrice, N., Meek, S., ... Aitken, A. (2002). Phosphorylation-dependent interactions between enzymes of plant metabolism and 14-3-3 proteins. The Plant Journal, 18, 1-12. http://dx.doi.org/10.1046/j.1365-313X.1999.00417.x

Rapp, U., \& Hedrich, R. (2007). TPK1, a Ca 2-regulated Arabidopsis vacuole two-pore K channel is activated by 14-3-3 proteins. The Plant Journal, 52, 449-459. http://dx.doi:org/10.1111/j.1365-313X.2007.03255.x

Rienties, I. M., Vink, J., Borst, J. W., Russinova, E., \& Vries, S. C. (2005). The Arabidopsis SERK1 protein interacts with the AAA-ATPase $A t C D C 48$, the 14-3-3 protein GF14 $\lambda$ and the PP2C phosphatase KAPP. Planta, 221, 394-405. http://dx.doi.org/10.1007/s00425-004-1447-7

Roberts, M. R., Salinas, J., Collinge, D.B. (2002). 14-3-3 proteins and the response to abiotic and biotic stress. Plant Mol Biol, 50, 1031-1039. http://dx.doi.org/10.1023/A:1021261614491

Sehnke, P. C., Chung, H. J., Wu, K., \& Ferl, R. J. (2001). Regulation of starch accumulation by granule associated plant 14-3-3 proteins. Proc Natl Acad Sci, 98, 765-770. http://dx.doi.org/10.1073/pnas.98.2.765

Saalbach, G., Schwerdel, M., Natura, G., Buschmann, P., Christov, V., \& Dahse, I. (1997). Over-expression of plant 14-3-3 proteins in tobacco: enhancement of the plasmalemma K conductance of mesophyll cells. FEBS Lett, 413, 294-298.

Sairam, T. (1994). Effect of moisture stress on physiological activities of two contrasting wheat genotypes. Ind $J$ Exp Biol, 32, 593-594. http://dx.doi:org/10.1111/j.1365-313X.2006.02955.x

Schoonheim, P. J., Sinnige, M. P., Casaretto, J. A., Veiga, H., Bunney, T. D., Quatrano, R. S., ... Anderson, H. W. (2007). 14-3-3 adaptor proteins are intermediates in ABA signal transduction during barley seed germination. Plant J, 49, 289-301. http://dx.doi:org/10.1111/j.1365-313X.2006.02955.x

Schultz, T. F., Medina, J., Hill, A., \& Quatrano, R. S. (1998). 14-3-3 proteins are part of an abscisic acid-VIVIPAROUS1 (VP1) response complex in the Em promoter and interact with VP1 and EmBP1. The Plant Cell Online, 10, 837. http://dx.doi.org/10.2307/3870669

Sehnke, P. C., DeLille, J. M., \& Ferl, R. J. (2002). Consummating signal transduction: the role of 14-3-3 proteins in the completion of signal-induced transitions in protein activity. The Plant Cell Online, 14, Supplement 1 , S339. http://dx.doi.org/10.1105/tpc.010430

Tas, S., \& Tas, B. (2007). Some physiological responses of drougt stress in wheat genotypes with different ploidity in Turkiye. World Journal of Agricultural Sciences, 3, 178-183.

van den Wijngaard, P. W., Sinnige, M. P., Roobeek, I., Reumer, A., Schoonheim, P. J., Mol, J. N., ... Anderson, H. W. (2005). Abscisic acid and 14-3-3 proteins control K channel activity in barley embryonic root. Plant J, 41, 43-55. http://dx.doi:org/10.1111/j.1365-313X.2004.02273.x

Xiong, L., Wang, R. G., Mao, G., \& Koczan, J. M. (2006). Identification of drought tolerance determinants by genetic analysis of root response to drought stress and abscisic acid. Plant Physiol, 142, 1065. http://dx.doi.org/10.1104/pp.106.084632

Yan, J., Wang, J., \& Zhang, H. (2002). An ankyrin repeat-containing protein plays a role in both disease resistance and antioxidation metabolism. The Plant Journal, 29, 193-202. http://dx.doi.org/10.1046/j.0960-7412.2001.01205.x

Yan, J., He, C., Wang, J., Mao, Z., Holaday, S. A., Allen, R. D., Zhang, H., \& Anderson, H. W. (2004). Overexpression of the Arabidopsis 14-3-3 protein GF14 lambda in cotton leads to a "stay-green" phenotype and improves stress tolerance under moderate drought conditions. Plant Cell Physiol, 45, 1007-1014. http://dx.doi.org/10.1093/pcp/pch115

Yohei, Takahashi, Toshinori, Kinoshita, \& Ken-ichiro, Shimazaki. (2007). Protein phosphorylation and binding of a 14-3-3 protein in vicia guard cells in response to ABA. Plant Cell Physiol, 48, 1182. http://dx.doi.org/10.1093/pcp/pcm093

Zhang, H., Wang, J., \& Goodman, H. M. (1997). An Arabidopsis gene encoding a putative 14-3-3-interacting protein, caffeic acid/5-hydroxyferulic acid O-methyltransferase1. Biochimica et Biophysica Acta (BBA)-Gene Structure and Expression, 1353, 199-202. http://dx.doi.org/10.1016/S0167-4781(97)00096-1 